\title{
DoE/MT/93006--12
}

\section{Investigation of Heat Transfer and Combustion in the Advanced Fluidized Bed Combustor (FBC)}

\section{Technical Progress Report January 1998}

\author{
By: \\ Seong W. Lee
}

RECEIVED

AUG 171998

O.TI

Work Performed Under Contract No.: DE-FG22-93MT93006

For

U.S. Department of Energy

Office of Fossil Energy

Federal Energy Technology Center

P.O. Box 880

Morgantown, West Virginia 26507-0880

Morgan State University

School of Engineering

Baltimore, Maryland 21239

HASTEF 


\section{Disclaimer}

This report was prepared as an account of work sponsored by an agency of the United States Government. Neither the United States Government nor any agency thereof, nor any of their employees, makes any warranty, express or implied, or assumes any legal liability or responsibility for the accuracy, completeness, or usefulness of any information, apparatus, product, or process disclosed, or represents that its use would not infringe privately owned rights. Reference herein to any specific commercial product, process, or service by trade name, trademark, manufacturer, or otherwise does not necessarily constitute or imply its endorsement, recommendation, or favoring by the United States Government or any agency thereof. The views and opinions of authors expressed herein do not necessarily state or reflect those of the United States Government or any agency thereof. 


\section{DISCLAIMER}

Portions of this document may be illegible electronic image products. Images are produced from the best available original document. 


\section{ABSTRACT}

This technical report summarizes the research conducted and progress achieved during the period from October 1, 1997 to December $31,1997$.

Numerical simulation on the flow patterns/the velocity profiles was conducted and predicted. The test conditions and input boundary conditions are summarized.

The flow patterns of the side view/top view are predicted along with stream lines. When the flow reached to the secondary air input of the lower air injection nozzles, the flow pattern was changed from a laminar flow to a turbulent flow.

The velocity profiles at various locations of the combustor chamber were predicted. The velocity at the center of the combustor is greater than that of the wall region. The velocity of the top section is also greater than that of the lower section. The swirling velocity is reduced in both directions of the wall and the center of the combustor chamber. The velocity increased from the wall region to the center region at the top section of the secondary air injectors.

Numerical modeling/simulation will be continued to determine the species profiles, temperature profiles, mass fraction profiles, and heat flux and heat transfer coefficient profiles. In addition, experimental test on the hot combustor model will be conducted and analyzed to compare with the numerical simulation results. 
TABLE OF CONTENTS

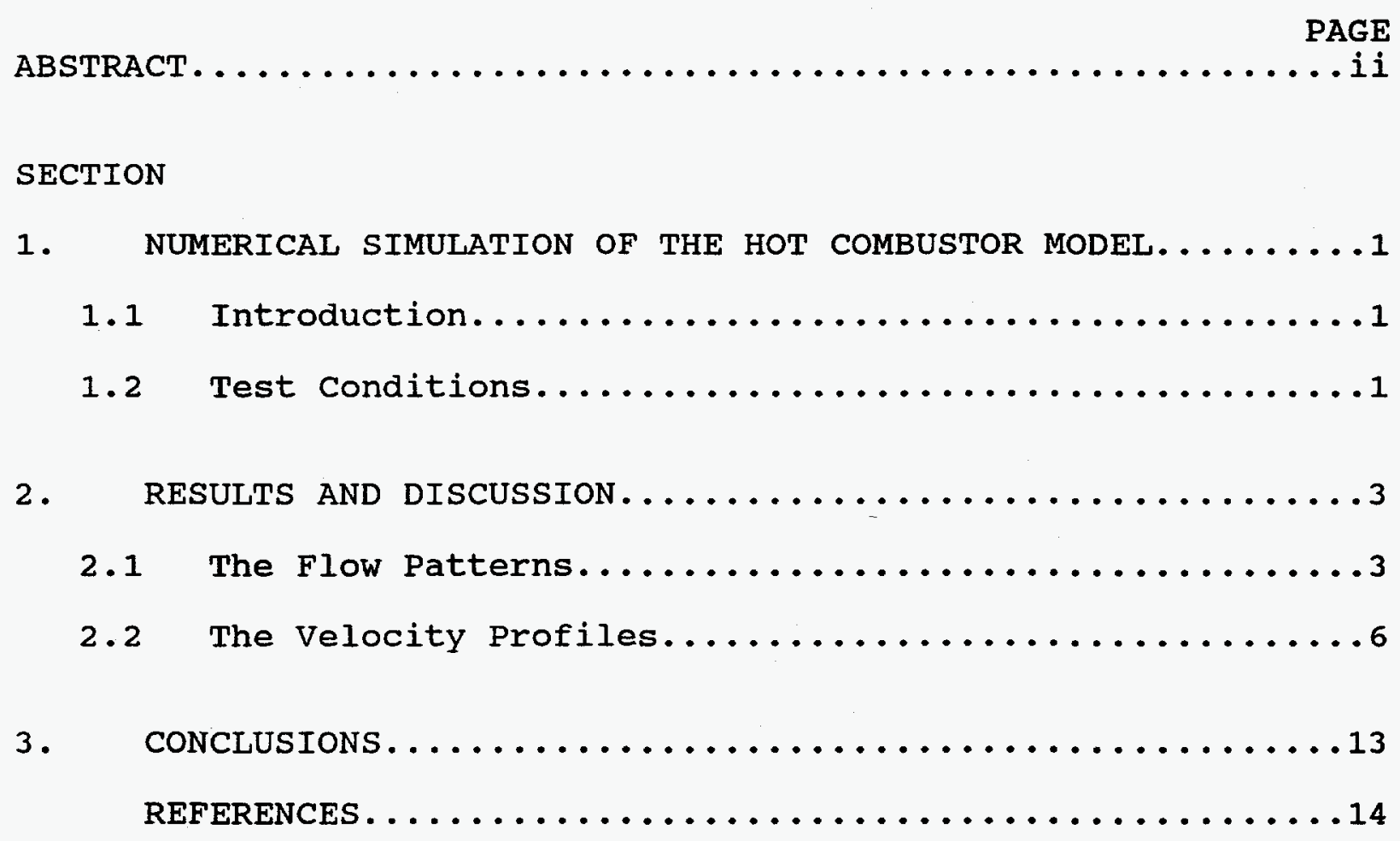




\section{SECTION 1}

NUMERICAL SIMULATION OF HOT COMBUSTOR MODEL

\subsection{Introduction}

The purpose of the numerical simulation on the advanced swirling fluidized bed combustor (hot model) is to determine the hot flow patterns, pressure/velocity profiles, species concentration profiles, temperature profiles, and heat flux/ heat transfer coefficients. Basic governing equations, species conservation equations, and radiation heat transfer model were introduced in the previous report [1].

\subsection{Test Conditions}

The combustor chamber has the height of $73 \mathrm{~cm}$, the inner diameter of $14 \mathrm{~cm}$, the outer diameter of $17.6 \mathrm{~cm}$. Two sets of secondary air nozzles are installed on the combustor wall at different levels of the height; $22.2 \mathrm{~cm}$ height for bottom nozzles and $41.6 \mathrm{~cm}$ height for top nozzles, respectively. Each nozzle is separated at 90 degree around combustor wall. The secondary air is injected into the combustor chamber from the nozzles with 45 degree of yam angle and zero degree of pitch angle. The fuel nozzle is installed at the bottom of the combustor. The primary air is provided to the bottom part of the combustor along with the fuel supply pipe.

The test conditions and input boundary conditions are summarized in Table 1. 


\section{Table 1 Test Conditions for simulations}

\begin{tabular}{|c|c|c|}
\hline Combustor Inner Diameter(ID) & $\mathrm{cm}$ & 14.0 \\
\hline Combustor outer Diameter(OD) & $\mathrm{cm}$ & 17.6 \\
\hline Combustor Height. & $\mathrm{cm}$ & 73.0 \\
\hline Top Secondary Nozzle & $\mathrm{cm}$ & 41.6 \\
\hline Top Nozzle No. & & 4 \\
\hline Bottom Secondary Nozzle & $\mathrm{cm}$ & 22.2 \\
\hline Bottom Nozzle No. & & 4 \\
\hline Nozzle Size (OD/ID) & $\mathrm{mm}$ & $10 / 8.5$ \\
\hline Nozzle Yam Angle & degree & 45 \\
\hline Nozzle Pitch Angle & degree & 0 \\
\hline Secondary Air Flow Rate & $\mathrm{m}^{3} / \mathrm{min}$ (total) & 0.11 \\
\hline Primary Air Flow Rate & $\mathrm{m} 3 / \mathrm{min}$ & 0.0036 \\
\hline Fuel supply Pipe (OD/ID) & $\mathrm{mm}$ & $9.52 / 7.62$ \\
\hline Height of Fuel Nozzle & $\mathrm{cm}$ & 7.63 \\
\hline No. of Fuel Nozzle Holes & & 5 \\
\hline Hole Size of Fuel Nozzle & $\mathrm{mm}$ & 1.8 \\
\hline Fuel Flow Rate & $\mathrm{m}^{3 / m i n}$ & 0.0092 \\
\hline Type of Fuel & Natural Gas & $\mathrm{CH} 4$ \\
\hline \multicolumn{3}{|l|}{ For Input Air/Fuel; } \\
\hline Temperature & $\mathrm{C}$ & 22 \\
\hline Pressure & atm & 1 \\
\hline
\end{tabular}


SECTION 2

RESULTS AND DISCUSSION

\subsection{The Flow Patterns}

The flow patterns of the side view/top view on the advanced swirling fluidized bed combustor are shown along with stream lines in Figures 1 and 2 respectively. The flow starts from the fuel nozzle and swirling flow along the combustor height. The diameter of the swirling flow increased as the gas flow moved upward along the combustor chamber axis.

When the flow reached to the secondary air input of the lower air injection nozzles, the flow pattern was changed from a laminar flow pattern to a turbulent flow pattern. When the flow reached to the secondary air input of the upper air injection nozzles, a horizontal flow circle was formed along the nozzles. These results showed the pressure balance in $\mathrm{K}$ direction where the swirling flow could reach to the combustor wall [2].

The stream lines at the bottom section of Figure 1 are same stream lines as the center zone of Figure 2. Similarly, the stream lines at the upper zone in Figure 1 are same stream lines as near the combustor wall in Figure 2. Four stream lines at the bottom/center zone sharply stretched out on the region where four nozzles are located along with a fuel injector. The results indicated that the flow patterns of radial velocity components at the fuel injection could be simulated by our test conditions.

The swirling flow patterns in Figures 1 and 2 are very similar to the observed flow patterns [3] in the combustion test. During the experimental test, the fire flame patters and condi- 
Figure 1 Flow Patterns of the Side View in the Combustor

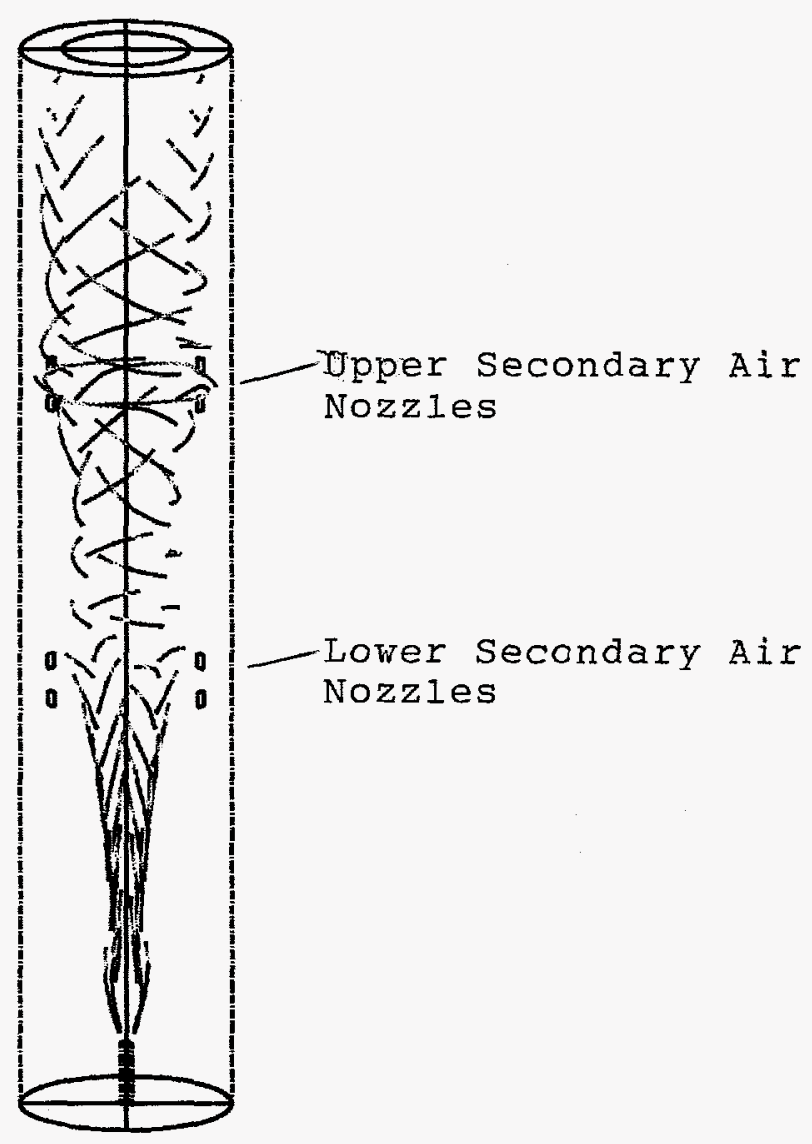

$x$ SWIRLING COMBUSTOR HOT FLOW SIMULATIONS

2 Streomlines 
Figure 2 Flow Patterns of the Top View in the combustor

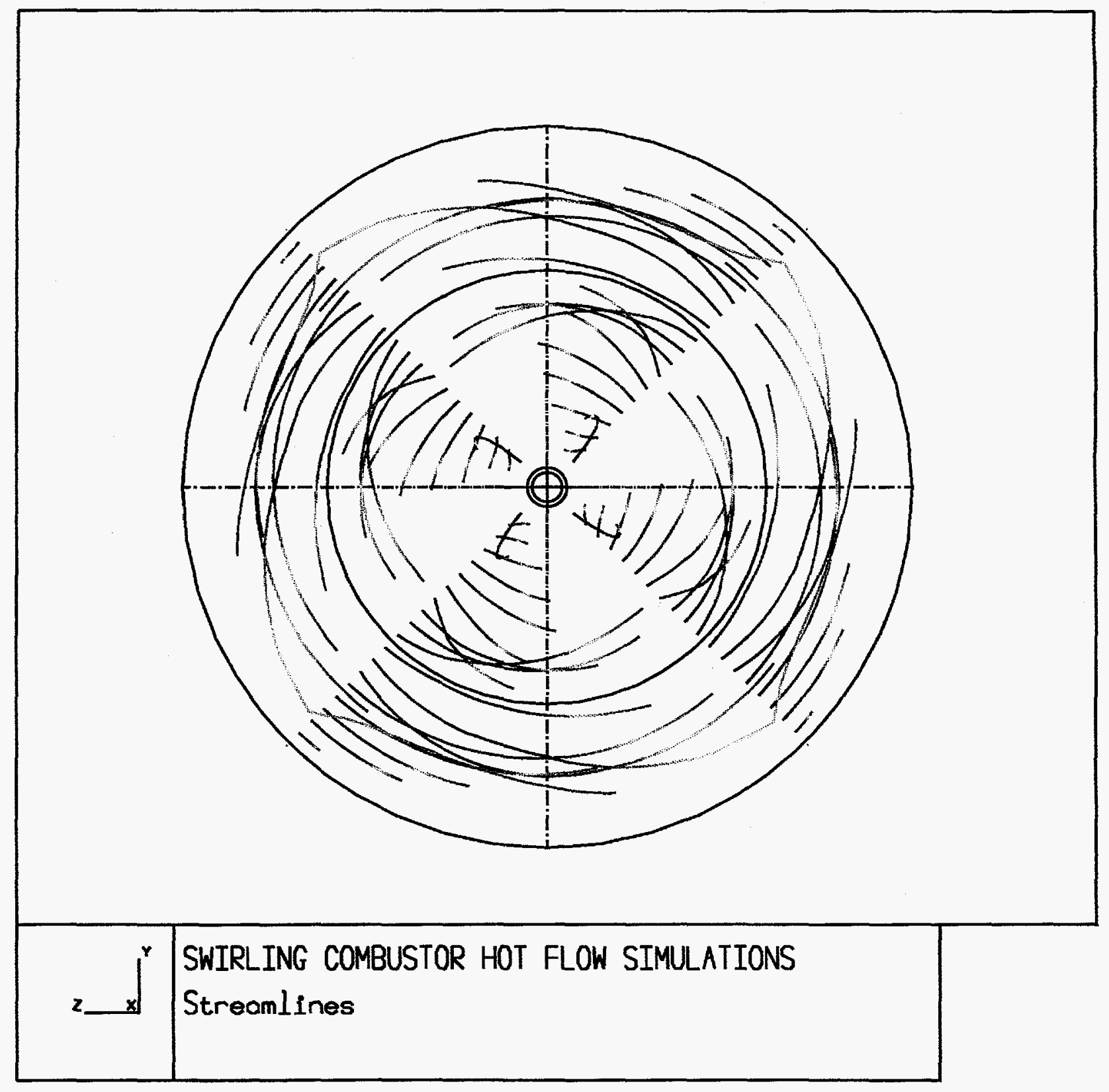


tions are observed and recorded by VCR.

\subsection{The Velocity Profiles}

Figure 3 shows the side view of the velocity profile in the vertical direction. The velocity at the center is greater than that of the wall region. The velocity of the top section is also greater than that of the lower section.

Figure 4 shows velocity profiles at eight levels; $K=6,10$, $20,30,40,50,60$ and $70[4]$. Figure 5 shows the velocity profiles for the fuel nozzle injector at the level of $K=10$. Figure 6 shows velocity profiles of the lower secondary air nozzle at the level of $\mathrm{K}=30$. Figure 7 shows velocity profiles of the upper secondary air nozzle at level $K=50$.

At level $\mathrm{K}=10$, the velocity at near the wall is about 0.32 $\mathrm{m} / \mathrm{s}$. The velocity is reduced to about $3.77 \mathrm{~m} / \mathrm{s}$ at near the center as shown in Figure 5. It is worth to note that the swirling velocity is reduced in both directions of the wall and the center of the combustor chamber. The highest velocity is about $4 \mathrm{~m} / \mathrm{s}$ at near the wall.

At the secondary air injection levels, $K=30$ and $K=50$, the outside velocity is greater than that of the center as shown in Figures 6 and 7 . The outside velocity is reduced to less than the center velocity in the level between the two secondary air injectors at $\mathrm{K}=40$ as shown in Figure 4 . In addition, the velocity increased from the wall region to the center region at the top section of the secondary air injectors.

At level $\mathrm{K}=30$, the velocity of the secondary air nozzle 
outlet is about $3.4 \mathrm{~m} / \mathrm{s}$. When the air injected into the combustor chamber, the velocity decreased rapidly. However, the whole chamber achieved the swirling flow with a core diameter as shown in Figure 6.

At level $\mathrm{K}=50$, the velocity of the secondary air nozzle outlet is about $3.44 \mathrm{~m} / \mathrm{s}$ as shown in Figure 7 . The velocity formed the swirling flow with a core diameter, which is about half size at $K=30$. 


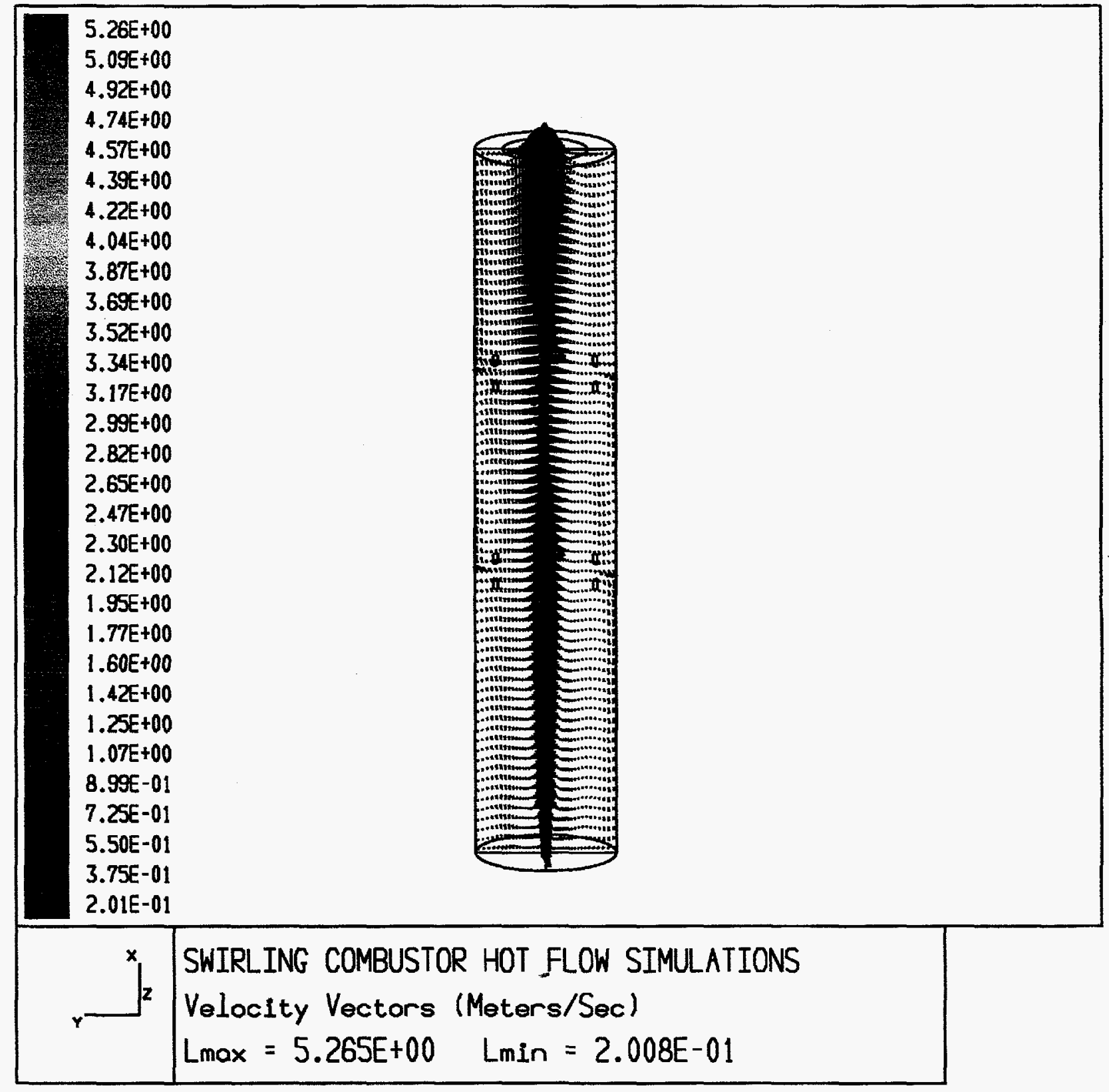

Figure 3 Velocity Profiles of the Vertical Direction in the Combustor 


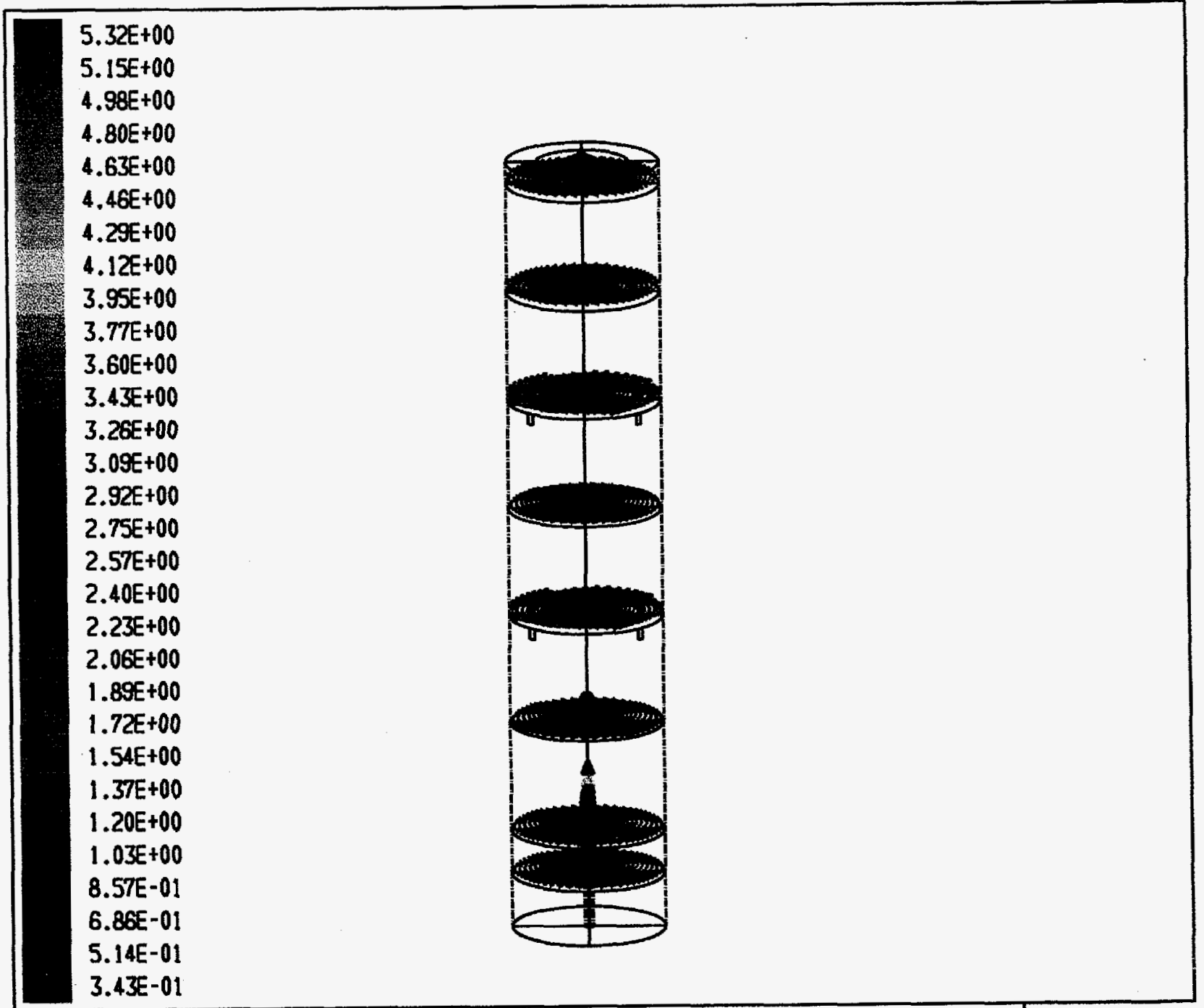

\begin{tabular}{|l|l|}
\hline$x$ & $\begin{array}{l}\text { SWIRLING COMBUSTOR HOT FLOW SIMULATIONS } \\
\text { Velocity Vectors (Meters/Sec) } \\
\text { Lmax }=5.319 E+00 \quad \text { Lmin }=3.427 E-01\end{array}$ \\
\hline
\end{tabular}

Figure 4 Velocity Profiles of the Vertical Direction at Different
Levels $(K=6,10,20,30,40,50,60$, and 70$)$ 


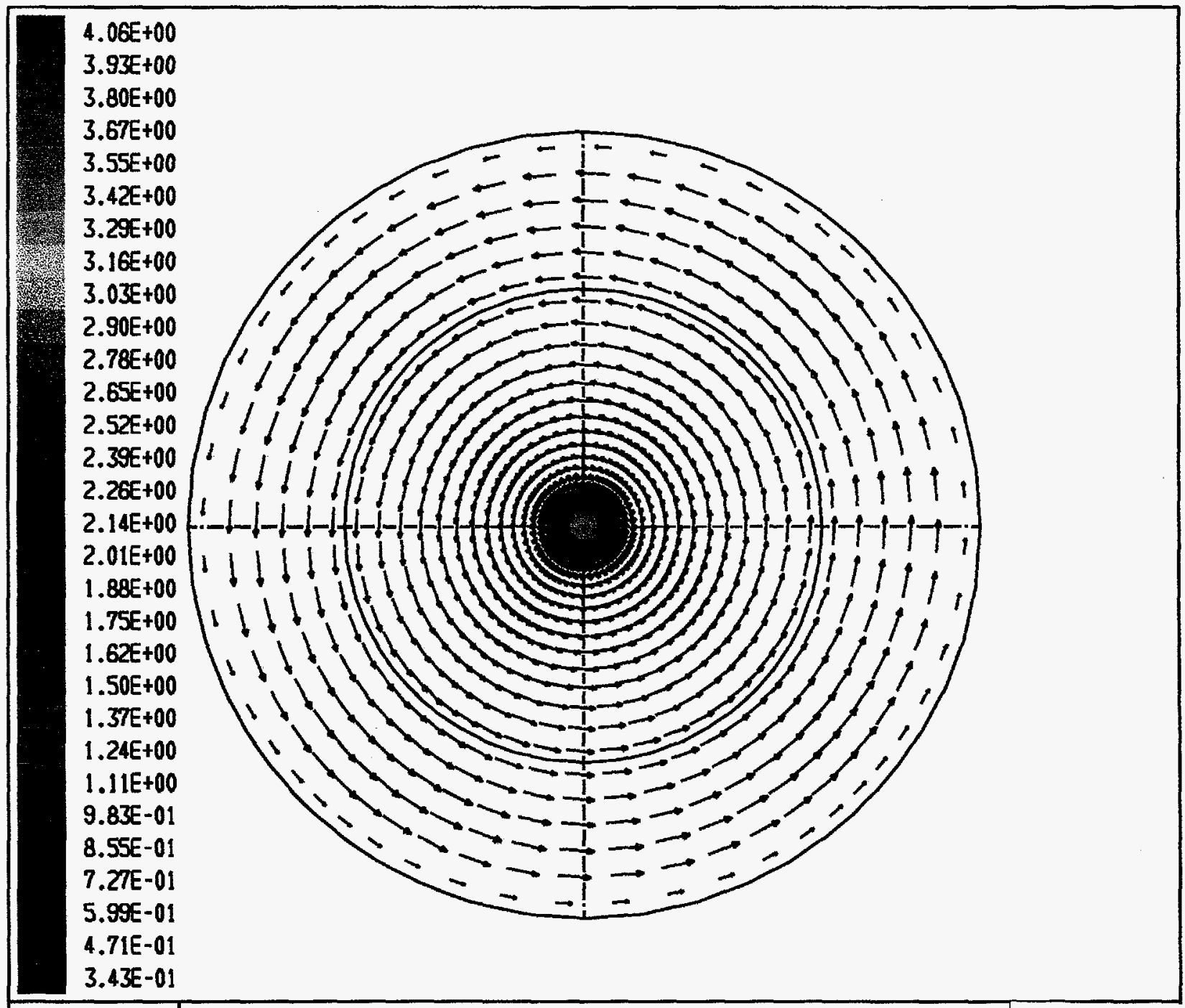

\begin{tabular}{|c|c|}
\hline $\int_{-x}^{Y}$ & $\begin{array}{l}\text { SWIRLING COMBUSTOR HOT FLOW SIMULATIONS } \\
\text { Velocity Vectors (Meters/Sec) } \\
\text { Lmax }=4.058 E+00 \quad \text { Lmin }=3.427 E-01\end{array}$ \\
\hline
\end{tabular}

Figure 5 Velocity Profiles at Level $K=10$ in the Combustor 


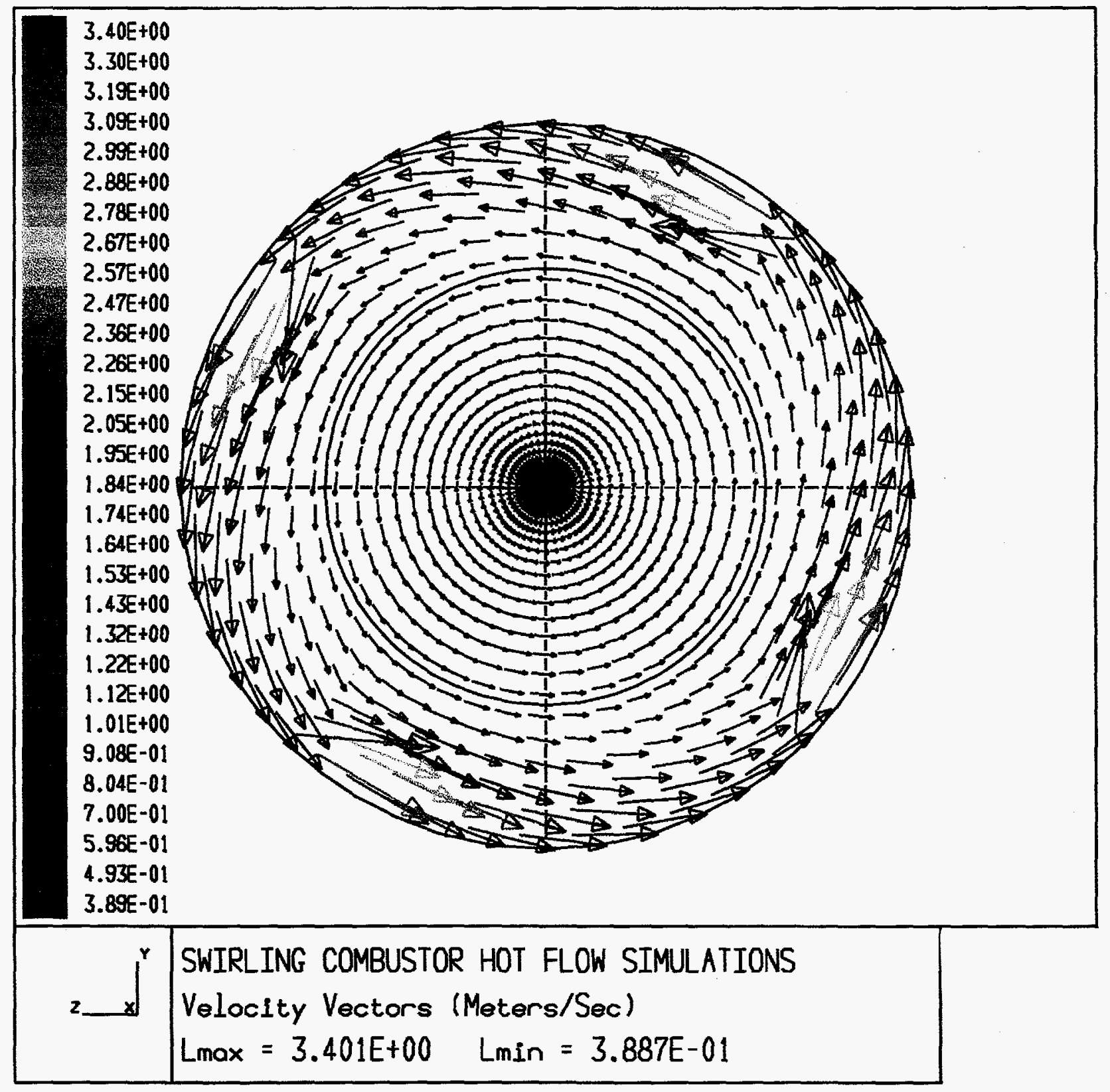

Figure 6 Velocity Profiles at Level $\mathrm{K}=30$ in the Combustor 

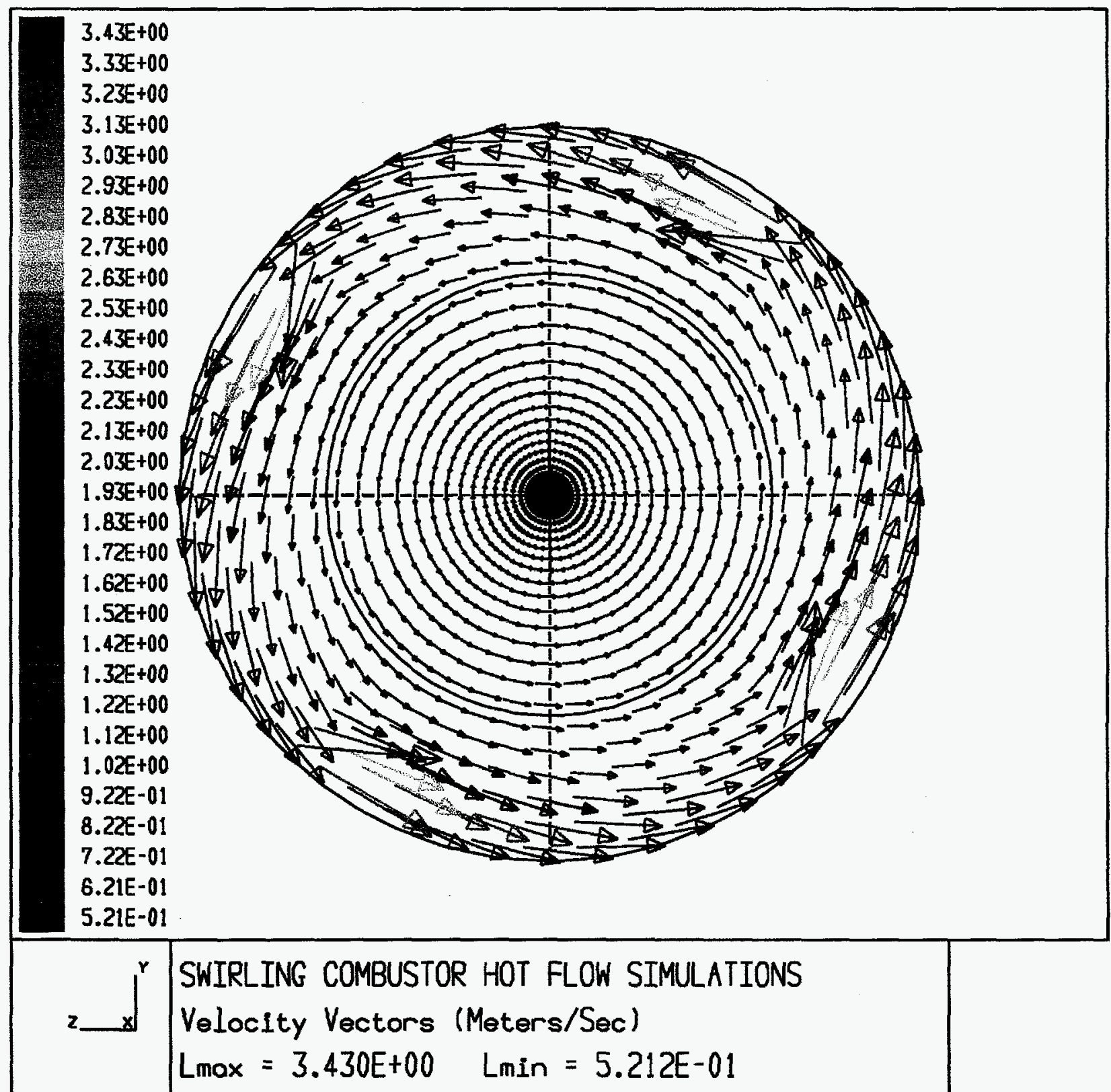

Figure 7 Velocity Profiles at Level $k=50$ in the Combustor 


\section{SECTION 3}

\section{CONCLUSIONS}

Numerical simulation on the flow patterns and velocity profiles was conducted using a computational fluid dynamics (CFD) code, Fluent, which was loaded on to the supercomputer Cray J916 of Morgan state University. The test conditions and input boundary conditions are summarized. The flow patterns of the side view/top view are predicted along with stream lines. When the flow reached to the secondary air input of the lower air injection nozzles, the flow pattern was changed from a laminar flow to a turbulent flow.

The velocity profiles at various locations of the combustor chamber were predicted. The swirling velocity is reduced in both directions of the wall and the center of the combustor chamber.

Numerical modeling/simulation will be continued to determine the species profiles, temperature profiles, mass fraction profiles, and heat flux/heat transfer coefficient profiles. The experimental test on the hot combustor model will be conducted and analyzed to compare with the numerical simulation results. 


\section{REFERENCES}

[1] Lee, S.W., Technical Progress Report, No.16, U.S. DOE, FETC, October 1997.

[2] Fluent User's Guide, Vol.4, Chapter 19, 1995.

[3] Lee, S.W., Technical Progress Report, Nos.14, 15, U.S. DOE, FETC, April/July 1997.

[4] Hoffmann, K.A. et. at, Computational Fluid Dynamics, 3rd Ed. Vol. 1, Chapter 9, Vol.2, Chapter 13. Engineering Education, System, KS, 1995. 